\title{
Cordonnier Sepsis Syndrome Requiring Transfer to Intensive Care Unit
}

National Cancer Institute

\section{Source}

National Cancer Institute. Cordonnier Sepsis Syndrome Requiring Transfer to Intensive

Care Unit. NCl Thesaurus. Code C138319.

Any sepsis syndrome requiring transfer to an intensive care unit. 